\title{
A Mediterranean japonica rice (Oryza sativa) cultivar improvement through anther culture.
}

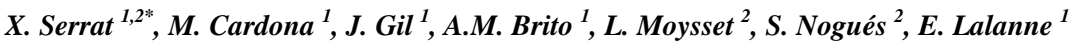 \\ (1) Germplasm platform, Oryzon Genomics, S.A., Cornellà de Llobregat, Spain. \\ (2) Departament de Biología Vegetal, Universitat de Barcelona, Barcelona, Spain. \\ * Corresponding author: xserragu8@alumnes.ub.edu \\ Phone (+34) 934033 717; Fax (+34) 934112842
}




\section{Abstract}

Certified seed producers systematically select and propagate registered varieties year after year in order to maintain their uniformity and the original registered cultivar traits. However, natural mutations, spontaneous breeding between varieties and alien grain contamination can introduce undesirable variability. NRVC 980385 is a temperate japonica rice cultivar (Oryza sativa ssp. japonica) first registered in Spain in 2002. In 2005 certification tests detected a plot differing from the original traits in terms of uniformity and height suggesting the presence of a certain heterozygosis. This material was therefore seen as an opportunity to obtain newly stabilized doubled haploid (DH) lines which could compete in the Spanish short grain seed market. In this study, an in vitro anther culture protocol is defined which also covers the field tests selection to obtain four new, improved and stabilized DH derived lines ready to be registered for commercial proposes. This took just four years from the initial anther collection until new lines were grown in large scale field trials. Consequently, this protocol reduces the time for obtaining field assessed DH lines thereby having considerable advantages over other techniques by both maintaining the original registered cultivars and/or generating new derived varieties.

Key words: In vitro, Anther culture, Rice, Dihaploid, Doubled haploid. 


\section{Introduction}

In Spain, artificial breeding varieties obtained through genealogic selection of ancient Spanish varieties and artificial breeding (Herruzo 1986) started to displace traditional varieties and acclimatized foreign varieties about 1940. In the 60's new semi-dwarf varieties were obtained to respond to the new production techniques based on mechanization (Campos et al. 1966). In 2000, rice varieties obtained by breeding coupled to genealogic selection started to compete with others obtained through more a selection techniques such as molecular marker assisted-selection and doubled haploid (DH) selection. This technique help plant breeders to obtain new varieties through a more precise and faster characters selection, and consequently, lots of new genetically improved rice varieties had appeared, reducing cultivar lifetime in the Spanish market (Català et al. 2007; Català et al. 2009).

The anther culture technique was first developed in rice by Niizeki and Oono (1968). This technique allows one to obtain completely stabilized DH plants which bypass the inbreeding process (Brar and Khush 2006; Germana 2011). It is the fastest method for DH production as it only takes between 8 to 9 months (Agache et al. 1989). This technique manipulates the male sex cells in immature anthers, to induce haploid callus formation, which are subsequently converted to double haploid embryos (Niizeki and Oono 1968). Genetic recombination occurs during haploid sex cell production so that each microspore (immature pollen) which is produced is genetically unique. Consequently, each DH line obtained in this way will produce a new stabilized and unique line. This breeding tool has been used not only to establish parental pure lines saving the long inbreeding process, but also to speed up descendant's selection after an artificial cross, bypassing the classical pedigree selection process (Martinez et al. 1996; Courtois 1993; Moon et al. 2003)

Transgenic pest and herbicide resistant lines have been also developed in public institutes using Spanish rice varieties (Coca et al. 2004; Messeguer 2003; Marfa et al. 2002) with no commercial results to date, although foreign Clearfield herbicide resistant mutant lines have been recently introgressed into mid-grain rice and produced in Spain by Cooperativa de Productores de Semillas de Arroz, S.C.L. (Copsemar, SCL). Its commercialization is expected in the near future, although the ecological concerns about the rapid resistance transmission to weedy rice reported (Shivrain et al. 2008; Kaloumenos et al. 2013; Goulart et al. 2012). 
When a rice cultivar has been cultivated for many years, agronomic traits may begin to differ from the original traits as a result of natural mutations and spontaneous breeding between cultivars due to seed stock contamination in storage works, mechanical harvesters, seed dryers and transport, see Rice Seed Health (IRRI 1988). Certified Seed production programmes are currently working to counter this phenomenon through plot supervision and specific tests in order to guarantee the maintenance of its identity, genetic purity and physical, physiological and sanitary qualities (CIAT 1981).

The general suggested procedure for sowing panicle-rows or plant-rows (Briggs and Knowles 1967; Jennings et al. 1979) is commonly used to ensure the uniformity of breeder seed by way of the elimination of off-types that could result from residual heterozygosity. Breeder seed also called G-0 or Pre-Base 5 (PB5) plants are grown and usually 10 spikes collected from each breeder seed plant are sown in rows the following year, this is G-1 or PB4 seed. A single 10-row group showing the highest visual uniformity and fidelity to the original variety traits is selected by comparing data between rows and within rows. Only one row is harvested among the best 10-row groups, and its self-pollinated seedlings (called G-2 or PB3) are grown next year in a separate plot. At this point, several traits such as productivity and uniformity are supervised under pre-defined tests to select the Stage I foundation seed (also called PB2). This seed is then grown to obtain Stage II foundation seed (also called Base seed), and finally Stage II foundation seedlings are grown in order to obtain R1 and R2 certified seed to be sold commercially.

Different countries use slightly different procedures and tests to obtain similar results. This depends mainly on government regulation and the amount of certified seed needed to satisfy the market: see Silva et al. (1988), the Philippines; Rao (1988), India; Muñoz and Rosero (1988) and the book from Centro Internacional de Agricultura Tropical (CIAT 1981), Colombia; Masajo et al. (1988), Colombia and Africa; Botchey (1988) and Asea et al. (2010), Africa; Boletín Oficial del Estado (BOE 2010), Spain; INIA report, Venezuela (Torres et al. 2006) and; in general, Rice Seed Health from the International Rice Research Institute (IRRI 1988).

NRVC 980385 is a temperate japonica rice (Oryza sativa) cultivar derived from a traditional cultivar called Bahia which in turn was derived from the Balilla cultivar (Herruzo 1986). It was registered in 2002, and certified seeds have been produced and distributed by the rice farmers 
cooperative called La Càmara Arrossera del Montisà, SCCL (from now on La Càmara). Since then it has been grown in the Ebro River Delta at high and constant percentages when compared with other japonica varieties (Català et al. 2007). It is acclimatized to Ebro River Delta and Albufera de València environmental conditions. It has good germinability in direct seeding and even under cold conditions (Català et al. 2010).

NRVC 980385 was the shortest rice cultivar grown in the Ebro River Delta from 2002 until 2005, but new shorter japonica varieties have appeared in the rice seed market since (Català et al. 2007). In the Mediterranean climatic region, the weather is usually windy and rainy at the end of the growing season; therefore NRVC 980385 is more easily affected by lodging phenomena than are shorter competitor cultivars. Reduction of plant height has traditionally been the main target in order to improve lodging resistance (Keller et al. 1999) and semi-dwarf lines were introduced to prevent lodging and increase yield during the "green revolution” (Keller et al. 1999; Khush 2001; Sasaki et al. 2002).

The objectives of this study are 1) to produce NRVC 980385-derived DH lines from a seed batch showing heterozygosity from an undetermined origin and 2) to select in controlled environment (i.e. greenhouse) and field conditions the best lines showing enhanced productivity, uniformity and short plant height, while at the same time maintaining traditional NRVC 980385 rice qualities and characteristics as demanded by the local seed market. In order to reach theses aims we developed an in vitro anther culture protocol that allowed us to produce in a short time four new improved and stabilized DH derived lines ready to be registered for commercial proposes.

\section{Materials and methods}

\section{Plant material and growth conditions}

NRVC 980385 is a commercial temperate japonica rice cultivar grown in the Ebro River Delta region in the south of Catalonia (Spain). Plant material was obtained from a highly heterozygous NRVC 980385 seed batch which was first detected during certification test processes in 2005 by the La Càmara seed producer cooperative. One hundred seeds were sown in stages between January and March 2007 in greenhouse conditions at the Experimental Fields Service at the University of Barcelona (Fig. 1a). Plants were grown in 4 litre plastic containers filled with rice substrate: Floratorf peat moss (Floragard Vertriebs, Oldenburg) - vermiculite (2:1 v/v) substrate 
supplemented with Osmocote (The Scotts Company LLC, USA) controlled-release fertilizer mix [Osmocote Exact $(15+9+9+3 \mathrm{MgO}+$ micronutrients) for 6 months and Osmocote high $\mathrm{K}(11+$ $5+15+1.2 \mathrm{MgO})$ for 9 months (1:1), $1 \mathrm{gr} /$ litre of substrate]. One gram $\mathrm{CaCO}_{3}$ per peat litre was added to adjust the substrate $\mathrm{pH}$ (around 6).

\section{Tiller cold treatment, spike sampling and disinfection}

Tillers were selected in the booting stage, which is characterized by a panicle formation growing inside the flag leaf sheath (boot leaf). Distance between the atria of the last two leaves was previously correlated to the correct spikelet developmental stage for the NRVC 980385 cultivar, between 4 and $8 \mathrm{~cm}$ (Fig. 1b). Harvest time was from 8:00 to 9:30 as recommended by Chen et al. (1991). A three-step disinfection process was carried out as follows. Harvested tillers were soaked in $70 \%$ ethanol for 1 minute and rinsed four times with sterilized water. Surface sterilized tillers were then cold treated: 7 to 12 days at $7^{\circ} \mathrm{C}$ in polystyrene bags and in darkness to further enhance callus induction (Trejo-Tapia et al. 2002a; Trejo-Tapia et al. 2002b; Cai and Chen 1984; Lentini et al. 1997). Cold treated tillers were surface disinfected again with 70\% ethanol before dissection. Panicles were then obtained under sterile conditions from the tillers by removing the leaf sheaths (Fig. 2c). The third disinfection step was carried out before anther plating as follows. The first 41 bare panicles were soaked for 3 minutes in 70\% ethanol and rinsed five times in sterile distilled water. While the last 196 panicles were sterilized by soaking in 10\% sodium hypoclorite solution for 3 minutes which was supplemented with Tween 20 (30 drops L $\left.{ }^{-1}\right)$ and $\mathrm{HCl}$ 35\% (50 drops L ${ }^{-1}$ ), and followed by 1 minute in 70\% ethanol and rinsed 6 times in distilled water as described by Lentini et al. (1997). These were then plated.

\section{Anther Culture}

Anther derived callus induction was obtained using media Chu N6 (Chu et al. 1975) modified as follows: N6 standard salts and vitamins fortified with $1 \mathrm{~g} \mathrm{~L}^{-1}$ casein hydrolisate, $250 \mathrm{mg} \mathrm{L}^{-1} \mathrm{~L}$ proline, $2 \mathrm{mg} \mathrm{L}^{-1}$ 2,4 dichlorophenoxyacetic acid, $1 \mathrm{mg} \mathrm{L}^{-1}$ kinetin, $500 \mathrm{mg} \mathrm{L}^{-1}$ 2-(N-morpholino) ethane sulphonic acid (MES), $30 \mathrm{~g} \mathrm{~L}^{-1}$ sucrose and $3 \mathrm{~g} \mathrm{~L}^{-1}$ Gelrite. Sterilin $90 \mathrm{~mm}$ petri dishes (Sterilin LTD, Cambridge) were filled with $25 \mathrm{ml}$ media after autoclaving. Microspore stage determination was carried out in different stage panicles and spikelets to enhance anther culture efficiency (Fig. 1d). Anthers samples from the first plated panicles were fixed daily in acetic acidethanol (1:3) with $2 \% \mathrm{FeCl}_{3}$ for $24 \mathrm{~h}$, and stained with $2 \%$ acetocarmine for microspore stage 
determination following Mercy and Zapata protocol (1986), however, this procedure was stopped after one week of plating anthers as results matched the expected microspore developmental stage ratios. Yellow to slightly green spikelets (Fig. 1c) were found to be related to the optimum rate of late uninucleate microspore developmental stage, matching results obtained by Afza et al. (2000) and Shahjahan et al. (1992). Panicles were placed on sterile paper and spikelets were dissected under sterile conditions (Fig. 1c). As described by Lentini (Lentini et al. 1997), spikelet tips were first held with forceps and then the basal part was cut in the lower third part so that the anther filaments were cut at the same time. Anthers from selected spikelets that came from the same panicle were plated in each petri dish (Fig. 1e). Petri dishes were sealed using Parafilm (Pechiney Plastic Packaging Company, Chicago) and incubated at $24^{\circ} \mathrm{C}$ for 6 to 8 weeks until the first anthers to respond produced the first microcalli (Fig 1f). Anthers were cultured in darkness as light is not necessary to induce calli and in fact, darkness helps calli growth (Lentini et al. 1997). Anther plating was stopped as soon as the first microcalli had been obtained. Microcalli were transferred to fresh callus induction media and grown until $2 \mathrm{~mm}$ in diameter before transferring to callus regeneration media petri dishes.

Green plantlet regeneration was carried out using Chu N6 (Chu et al. 1975) standard salts and vitamins fortified with $1 \mathrm{~g} \mathrm{~L}^{-1}$ casein hydrolysate, $250 \mathrm{mg} \mathrm{L}^{-1} \mathrm{~L}$-proline, $1 \mathrm{mg} \mathrm{L}^{-1}$ naphthaleneacetic acid, 2 mg L ${ }^{-1}$ kinetin, $500 \mathrm{mg} \mathrm{L}^{-1}$ MES, $30 \mathrm{~g} \mathrm{~L}^{-1}$ sucrose and $3 \mathrm{~g} \mathrm{~L}^{-1}$ Gelrite. IWAKI 94 mm petri dishes (Asahi Techno Glass Corporation, Amagasaki) were filled with $25 \mathrm{ml}$ media. Regeneration was done at $25{ }^{\circ} \mathrm{C}$ and 50 to $70 \mu$ mols $\mathrm{m}^{-2} \mathrm{~s}^{-1}$ fluorescent light under a $16 / 8$ hours day/night photoperiod until plantlet formation occurred (Fig. 1g). Frequently, ploidy duplication occurs spontaneously in rice during the in vitro regeneration process; therefore no antimitotic compound was used.

Fully tiny formed R1 plantlets $(0.5-3 \mathrm{~cm}$ length) were first transferred to hormone free MS (Murashige and Skoog 1968) media tubes; the custom made $17 \mathrm{~cm}$ long in vitro glass tubes were filled with $12 \mathrm{ml}$ hormone free MS media: standard salts and vitamins fortified with $500 \mathrm{mg} \mathrm{L}^{-1}$ MES, $30 \mathrm{~g} \mathrm{~L}^{-1}$ sucrose and $2 \mathrm{~g} \mathrm{~L}^{-1}$ Gelrite for 2-3 weeks. Next, these R1 plantlets $(10-15 \mathrm{~cm})$ were then propagated using a propagation media (Fig. 1h) which is the same hormone free MS media except fortified with $0.5 \mathrm{mg} \mathrm{L}^{-1}$ 6-benzylaminopurine. Culture was carried out at $25^{\circ} \mathrm{C}$ and 50 to $70 \mu \mathrm{mol} \mathrm{m} \mathrm{s}^{-1}$ fluorescent light under a 16/8 hours day/night photoperiod and was extended 
so as to have enough R1 plants to carry on the ploidy determination and additional assays (Figs. 1 and 2).

All media components were supplied by Duchefa (Duchefa Biochemie BV, The Netherlands).

Medias were prepared using distilled water and the $\mathrm{pH}$ was adjusted to 5.7 by adding $\mathrm{KOH}$

(Sigma-Aldrich Co) solutions. All components including hormones were added before standard autoclave sterilization $\left(120^{\circ} \mathrm{C}\right.$ for 20 minutes $)$.

\section{Ploidy determination}

About $1 \mathrm{~cm}^{2}$ of newly formed leaf tips from each line were placed on $55 \mathrm{~mm}$ diameter plastic petri dishes; the tissue was then sliced and chopped into small pieces by addition of $1.6 \mathrm{ml}$ of lysis buffer and use of a razor blade and incubated for 14 minutes. Lysis buffer composition was $15 \mathrm{mM}$ Tris- $\mathrm{HCl} \mathrm{pH}$ : 7.5, 2 mM disodium EDTA, 0.5 mM spermine tetrahydrochloride, $80 \mathrm{mM} \mathrm{KCl,} 20$ $\mathrm{mM} \mathrm{NaCl}, 0.2 \%$ Triton X-100 and $\mathrm{pH} 7.5$ adjusted with $1 \mathrm{M} \mathrm{NaOH}$. The homogenate was filtered through a $33 \mu$ m nylon mesh. Then, $15 \mu \mathrm{l}$ propidium iodide was added to $600 \mu \mathrm{l}$ of filtered solution and after incubation for 30-45 minutes at room temperature, the fluorescence intensity of nuclei was measured using a Coulter EPIC XL flow cytometer (Beckman Coulter, Miami, FL) at the Cytometry Unit (Scientific and Technological Centers, University of Barcelona). Summit Software v4.3 (Cytomation, Fort Collins, Colorado) was employed for data analysis. Two diploid NRVC 980385 samples were used as the reference ploidy controls where the controls produced the same single peak. Accessions were classified as DH if they produced a clearly defined single peak corresponding to the peak of the diploid controls. Accessions producing a half fluorescence intensity peak were classified as haploids (Figure S1). The main haploid R1clones were discarded such that only one R1 haploid individual per line was kept.

\section{Propagation, ex-vitro Acclimatization and Seed Production}

R1 DH lines were in vitro propagated in tubes for two months using propagation media (Figs. 1h and 2) until a minimum of 100 clones from each line were obtained. Propagated R1 clones were ex-vivo acclimatized as follows: media was carefully removed from the roots using tap water and plants were transplanted into 96-well multipots and each pot was filled with $35 \mathrm{~cm}^{3}$ of rice substrate (Fig. 1i). Recently transplanted R1 plants were placed in an acclimatization tunnel inside the greenhouse. Relative humidity was reduced over $100 \%$ to $70 \%$ for two weeks. After the 
acclimatization process plants were transplanted to 4L plastic pots (3 plants per pot) filled with rice substrate and grown in greenhouse conditions as described in Plant materials and growth conditions, however, the temperature was maintained at $19^{\circ} \mathrm{C}$. R1 plants were fertilized during the panicle formation period using high ammonium (50\% Total N) soluble fertilizer (NPK 19+6+6) supplemented with $4 \% \mathrm{w} / \mathrm{w}$ micronutrients and $4 \% \mathrm{w} / \mathrm{w}$ iron chelate diluted in osmotized water with a final electroconductivity adjusted to 1200 micro Siemens. DH plants were harvested individually in May 2008 and R2 seeds from the most vigorous and shortest cycle lines were used for Experiment 1 in the summer (see below). A haploid individual from each haploid line was also acclimatized to check flow cytometric ploidy assay results. R1 plants were ratooned and fertilized again during the panicle formation period to obtain more R2 seed for further field trials (Table 1,

Figs. 1, 2).

\section{Experimental design of field trials}

Field trials were carried out in La Càmara fields. All plots were at least 15 meters apart from one another in order to avoid cross pollination. Distances between field trial and other rice fields were always more than 20 meters. Standard fertilization and field management principles were applied. At least eight plants were randomly selected from each line and experiment in order to record data measurements. General traits such as the number of spikes per plant, different height measurements, grain/spike phenological stage, uniformity, pests/diseases and plant shape were recorded weekly. Other specific traits such as fungal lesions on leaves, flag leaf width, length and angle, fungal infection in spikes, days to heading, spike position and exertion, and late flowering ratio were also recorded weekly. Plants were harvested at maturity to obtain the yield results. Three different experiments were performed as mentioned below.

Experiment 1 was designed to test basic agro-morphological traits mentioned above and to select the most interesting lines using R2 seeds obtained from the initial R1 regenerated population. In the summer of 2008, the first 10 lines (DH1 to DH10) were tested. R2 seeds were sown in greenhouse conditions just three weeks after harvesting the original propagated and acclimatized R1 DH lines (DH1 to DH10). R2 plants were planted in the field late in the season, on June 2nd 2008. In summer of 2009, ten more lines (DH11 to DH20) were tested, plots were more homogeneous in number of plants and planting was done throughout the whole growing season (Table 1). In both years, three to four leaf stage plantlets were transported to La Càmara 
Experiment 1 field, being hand-planted with a spacing of $25 \times 20 \mathrm{~cm}$ in small plots (Figure S2). NRVC 980385 plots were also planted in the same way and at the same time in order to compare results. This field was designed as follows: 18 plots ( 2 meters x 5 meters) were reserved for assessed lines and NRVC 980385 controls. The bottom margin of the Experiment 1 field corresponds to the 5 meters width access road; the distance from plots to the road was only 15 meters. A minimum 15 meters distance between lines and 20 meters to adjacent field was designed to avoid gene flow-mediated hybridization.

Experiment 2 field trials were carried out to test R3 seeds form Experiment 1 selected lines on a medium scale (Table 1). Parcels were planted by hand with a spacing of $25 \times 20 \mathrm{~cm}$ using almost all the available R3 seed; with parcels ranging from $1242 \mathrm{~m}^{2}$ to $4980 \mathrm{~m}^{2}$ in size (Table 2, Fig. 1j). The NRVC 980385 controls were also hand-planted in parcels adjacent to each DH line using the same format and field conditions as experimental plots so as to be able to compare results. Experiment 2 was performed twice as follows (Table 1):

DH3, DH8 and DH9 seeds obtained from experiment 1 (R3) and certified NRVC 980385 seeds were sown in 2009 in greenhouse conditions and hand planted in three rice parcels to assess traits as described above. DH3, DH8 and DH9 lines were grown in $4480 \mathrm{~m}^{2}, 2333 \mathrm{~m}^{2}$ and $4060 \mathrm{~m}^{2}$ parcels respectively. Field size was mainly determined by seed availability.

In 2010, Experiment 2 was repeated using R4 seed from DH3, DH8 and DH9 lines, and likewise, R3 seeds from DH12, DH16 and DH18 obtained in Experiment 1 were also assessed. Six additional NRVC 980385 fields were used as controls, one control per line, each one growing next to each study line. In this experiment, a similar number of plants and plot dimensions were used thanks to seed availability. DH3, DH8 and DH9 were grown in $1830.4 \mathrm{~m}^{2}, 1830.4 \mathrm{~m}^{2}$ and 1919.4 $\mathrm{m}^{2}$ parcels respectively, and DH12, DH16 and DH18 were grown in $1325.5 \mathrm{~m}^{2}, 1242 \mathrm{~m}^{2}$ and $1642.5 \mathrm{~m}^{2}$ parcels respectively.

Experiment 3 was a large scale field trial (Table1, Fig. 1k). R4 seeds from DH3, DH8 and DH9 lines were machine-sown in different areas, soils and fertilizer conditions in order to test the yield performance of each line under real conditions using standard seed production practices. Farmers' observations were also taken into account although traits recorded in Experiment 1 and 2 were also recorded weekly in Experiment 3.
Comentario [u1]: Aquests 2 parragrafs de expiremnt 1 els hem ajuntat, repassa qeu estigui be 
Two different fields were used per line. The fields were rented out by La Càmara to six different cooperative associate farmers. The sum of Ha per line in associate farmers' fields ranged from 4.5 to $4.8 \mathrm{Ha}$. Yield was tested and compared to the average NRVC 980385 yield obtained that year from seed production fields grown by La Càmara farmer associates.

DH3 was grown in 2.85 Ha and 1.93 Ha fields called Field No.1and Field No.2 respectively. Field No.2 was over fertilized. DH8 was grown in 3.57 Ha and 0.88 Ha fields called Field No.3 and Field No.4 respectively. Field No.3 was placed beside a NRVC 980385 registered seed production field and in this case control data was taken. Field No.4 was highly clayey and fertilized using natural guano. DH9 grown in 2.05 Ha and 2.41 Ha fields were called Field No.5 and Field No.6 respectively.

\section{Results}

\section{Anther culture and DH lines}

The DH lines obtaining from anther culture took a total of 233 days (Figs. 2 and S3). In our experimental conditions booting stage tillers were harvested late in the season, from June to September 2007 and in total 42,660 anthers originating from 237 spikes were sown over 53 days.

Sixty three out of 237 petri dishes were discarded due to contamination. Ethanol panicle disinfection resulted in a $40 \%$ plate contamination rate, while Clorox disinfection reduced contamination to $22.25 \%$, but no calli were obtained from this second sterilization process.

Anther plating and callus induction was stopped on the $53^{\text {rd }}$ day as soon as the first 4 anthers to respond produced the first globular and clear microcallus masses which were growing from different parts of the anthers (Fig. 1f). Microcalli grew during the regeneration process and produced green spots and small roots which were followed by shoot development (Fig. 1g). The first plantlets had fully formed 30 days after the regeneration process had begun (Fig. 2). The regeneration process yielded 42 green plantlets, 6 albinos and 1 green and white chimera.

Regenerated green plantlets represented $85.71 \%$ of the total plantlet regeneration. Flow cytometry assaying identified $29 \mathrm{DH}$ and 13 haploid lines (Fig. S1), thus DH lines represented 69\% of total green plantlet lines. One chimeric white and green plantlet was also analysed and was found to be a triploid plant. 
All DH green plantlet lines were efficiently propagated over a two month period giving a minimum of 100 plants per line. Plantlets were acclimatized and grown until maturity in greenhouse conditions. Acclimatized haploid individuals were dwarf and sterile as expected (Niizeki and Oono 1968), confirming flow cytometry results. DH line seedlings were harvested individually in May 2008 (Fig. 1) and plants were ratooned in order to obtain more seed for further experiments.

\section{Experiment 1}

The tiller per plant ratios were strongly increased in DH3, DH8 and DH9 lines (43\%, 70\% and $58 \%$ increases, respectively). DH3 was the shortest line, $15 \mathrm{~cm}$ shorter in comparison to NRVC 98038. This line did not look like NRVC 980385 as flag leaves were $41 \%$ longer. Line DH8 was about $10 \mathrm{~cm}$ shorter and flag leaves were only $16 \%$ longer. Furthermore, DH9 characteristics were most similar to those of NRVC 980385 but plants were only $8 \mathrm{~cm}$ shorter. Height results are shown in Figure 3a. Yield results were not taken into account since plots were too small and were of different sizes.

In 2009, the same Experiment 1 was carried out throughout the entire season, and 10 more lines, from DH11 to DH20 were tested. The number of plants per plot was more balanced. Height results were worse in comparison to results from the previous year (Fig. 3b). Finally, three lines were selected (DH12, DH16 and DH18) in accordance with yield, grain quality, plant height and other agronomic data (not shown).

\section{Experiment 2}

The first Experiment 2 performed in 2009 confirmed height results of DH3, DH8 and DH9 lines

(Fig. 4a). In this Experiment 2, tiller number increase was not significant in comparison to NRVC 980385, but lines were shorter than NRVC 980385 with DH3 being the shortest line (Figs. 4a and 4b). Yield results were very similar between lines and NRVC 980385 controls (Fig. 5a).

In order to confirm these results, Experiment 2 was repeated in 2010 using seeds harvested from the DH3, DH8 and DH9 lines from Experiment 2 performed the previous year. In addition, seedlings from three more lines (DH12, DH16 and DH20) which were also selected from the second Experiment 1 (2009) were tested. Height results were confirmed again for DH3, DH8 and DH9 (Fig. 4b), while height reduction was poor in second set lines. DH12, DH16 and DH20 lines 
were taller than controls, DH3, DH8 and DH9 assessed in the same experiment and in the same year (Figs. 4b and 4c), although height was almost acceptable for DH12 and DH16 (Fig. 4c). Yield results showed that DH12 had nearly 30\% more productivity, while yields in all other lines were similar to NRVC 980385 controls (Fig. 5).

\section{Experiment 3}

DH3 was once again the shortest line and also the distance between the panicle collar and the first leaf was clearly shorter than in that of NRVC 980385. In Field No. 2, the farmer over fertilized the field. Therefore, plants were taller and greener than in Field No.1 but yield was reduced and a higher level of fungal attack and lodging was detected. DH8 was grown in Field No.3 surrounded by an NRVC 980385 registered seed production field managed by the same farmer, from which control data was taken. Here, an average height reduction of $13 \mathrm{~cm}$ was scored. DH9 was clearly shorter than NRVC 980385 but plant shape was similar. Yield results are shown in Table 2 and

Fig. 5.

\section{Discussion}

An anther culture method based on the Lentini et al. protocol (1997) has been modified (see above) in our lab in order to efficiently obtain DH lines from NRVC 980385 cultivar plants grown in greenhouse conditions using spikes from plants sown in season which resulted in a high rate of callus production. However, in this study plants were sown from January to March, three months in advance of the normal growing season. Although the greenhouse was heated and NRVC 980385 is photoperiod insensitive, total irradiance was lower than in season and furthermore, 50 of the 100 donor plants had to be ratooned in order to obtain a second set of panicles. Ratooning plants and collecting spikes out of season could affect callus induction (Chen et al. 1991; Lentini et al. 1997; Raina and Zapata 1997; Guzman and Arias 2000; Heberlebors 1985), however Guzman and Arias (2000) reported higher green plantlet regeneration using ratooned Taipei-309 indica rice cultivar.

Although harvest time was from 8:00 to 9:30 am following Chen’s recommendations (1991) and the collected spikes were cold treated to enhance callus induction (Trejo-Tapia et al. 2002a; TrejoTapia et al. 2002b; Cai and Chen 1984), success in obtaining DH lines through anther culture is highly related to the amount of cultured microspores in the middle to late uninucleate stage present in plated anthers (Chen 1977; Gupta and Borthakur 1987; Bishnoi et al. 2000). This microspore 
developmental stage has been correlated to the distance between the atria of the last two leaves, but may vary depending on plant genotype and the environmental conditions in which it is placed (Lentini et al. 1997). Several authors have studied this correlation to improve anther culture and green plantlet regeneration rates, each one using different cultivars; Chen and Chen (1979) recommended collecting tillers with a distance of $5 \mathrm{~cm}$ between the atria of the last two leaves in Tainan 5 indica cultivar; Abbasi et al. (2011) reported 4 to $8 \mathrm{~cm}$ while Herath and Bandara (2011) reported 3 to 7 cm, both using indica-japonica hybrids. Our investigations in NRVC 980385 cultivar prior to this present work concluded that a 4 to $8 \mathrm{~cm}$ distance between the atria of the last two leaves and the flag leaf had the highest ratio of yellow to slightly green spikelets which also contained the highest ratio of middle to late uninucleate stage microspores according to Afta et al. (Afza et al. 2000). In the present study, the developmental stage in microspores was determined only in the first panicles since they matched our previous results. Efforts were therefore directed towards sowing as many anthers as possible in order to ensure enough DH lines were yielded. Nevertheless, the relationship between atria distances and microspore developmental stages could have changed during the plating process as donor plants were sown out of season and some of them had been ratooned.

Contamination is quite common in anther culture as spikelets cannot be completely sterilised without affecting anther viability (Lai et al. 1980). In our study, the high average contamination rate $(26.58 \%)$ in the anther derived callus induction process could be due to endogenous contamination and soft ethanol disinfection. This contamination rate also affected callus induction efficiency. The ethanol sterilisation process applied to the first 41 spikes resulted in a $40 \%$ plate contamination, thereby a Lentini’s Clorox sterilization process was followed (Lentini et al. 1997) and contamination incidence was reduced (22.5\%), however, no calli were obtained.

Although some authors succeeded in obtaining rice DH plantlets directly sowing anthers in onestep culture media without transferring to regeneration media so as to save time and resources (Karim and Zapata 1990; Marassi et al. 1993), two-step culture media protocols are widely used and described by authors (Lentini et al. 1997). As optimal media composition is highly affected by the genetic backup of the plants (Talebi et al. 2007) we adapted the protocol of Spanish Hispagran 
rice variety, genetically similar to NRVC 980385 (Wankhade et al. 2010), assessing N6 and MS salts and vitamins with different hormonal doses in order to induce anther derived calli formation and subsequent regeneration. N6 based medium yielded the best results in calli formation both in Hispagran and NRVC 980385, which agrees with results from other authors where the application of N6 medium is quite suitable for japonica rice, but usually not for indica rice cultivars (Reddy et al. 1985).

However, the anther-derived callus induction media for NRVC 980385 required few modifications on the previously established Hispagran protocol. The concentration of 2,4-D was reduced from $2.5 \mathrm{mg} \mathrm{L}^{-1}$ to $2 \mathrm{mg} \mathrm{L}^{-1}$, while kinetin $\left(1 \mathrm{mg} \mathrm{L}^{-1}\right)$ was maintain. This 2,4-D doses is in the range of that used by other authors (Shimada et al. 1999; Islam et al. 2004). Also, Herath et al. (2009) coincided assessing $2 \mathrm{mg} \mathrm{L}^{-1}$ 2,4-D and $1 \mathrm{mg} \mathrm{L}^{-1}$ kinetin in Hu lo tao japonica rice variety.

The use of $4 \%$ maltose as a carbon source was tested and rapidly discarded after different assessments with no callus formation although better results were obtained in indica rice by (Bagheri et al. 2009) using Iranian rice cultivars, (Niroula and Bimb 2009) using Nepalese varieties and (Javed et al. 2007) Indian rice cultivars. Proline was found to increase callus induction as reported by Cho and Zapata (1988), being $250 \mathrm{mg} \mathrm{L}^{-1}$ the optimal dose for both Hispagran and NRVC 980385 cultivars.

Albinism is a common problem in anther culture and generation of doubled haploids. Loss of chlorophyll pigments and incomplete differentiation of chloroplast membranes is partially influenced by environmental conditions, media composition and culture conditions, but genetic factors are the major determinants (Kumari et al. 2009; Yamagishi 2002). In our study, the proportion of albino plants among anther derived regenerated rice plants was only $14 \%$ which is quite low in comparison to 36\% in the Nipponbare rice model cultivar (Yamagishi et al. 1998). Although, Wang reported that frequencies of albino shoot forming microspore calli range from 5 to $90 \%$ in different temperate japonica cultivars (Wang et al. 1981). 
When in vitro anther cultures are performed, diploid plants are mainly homozygous DHs, but heterozygous diploids produced by the somatic tissue can occur, although in rice this is very unlikely (Chen et al. 1982). Some authors discard heterozygous diploids using isozyme analyses, RAPD markers, SCARs or SSRs to assess homozygosity (Germana 2011). In addition, conventional cytological techniques can be employed to determine the ploidy level of regenerated plants, but ploidy level can be more easily assessed by way of flow cytometry analysis (Bohanec 2003).

Our results indicated that plants were mainly DH (69\%), although one polyploid and some haploid plants were also detected. The DH percentage obtained among green regenerated plantlets is similar (56.4\%) to that obtained by Mercy and Zapata (1986). Consequently, flow cytometry helped us to discard non-DH plantlets thereby saving time and resources in in vitro propagation works.

In our case, field experiments resulted in high visual homogeneity in all offspring and no apparent character segregation was observed in any line.

A first selection was carried out when acclimatized plantlets were grown in greenhouse conditions until seed set. Only the first $20 \mathrm{DH}$ lines producing seeds were tested in Experiment 1 . All DH lines were stable and homogenous. Consequently, twenty healthy, stable and homogeneous DH lines having the shortest cycle were tested in Experiment 1 small field trials. Due to seed availability, the number of individuals per plot was from 50 to 120 plants in Experiment 1 performed in 2008. The number of tillers per plant appeared to be strongly increased in DH3, DH8 and DH9 lines (43\%, 70\% and 58\% increases respectively) in Experiment 1, however, no significant increases in this trait were obtained from subsequent experiments. It was suspected that this apparent increased tiller formation was due to the fact that NRVC 980385 controls had more plants per plot and it decreased the border effect in comparison to DH line plots.

Selection criteria was initially mainly focused on reduced height, enhanced tillering and enhanced yield, although all other weekly measures data records such as different height measurements, grain/spike phenological stage, uniformity, pests/diseases, plant shape, fungal lesions on leaves, flag leaf width, length and angle, fungal infection in spikes, days to heading, spike position and exertion and late flowering ratio were taken into account. Six lines were selected from Experiment 
1, three from the 2008 Experiment 1 field trial, which were considered to be the most interesting and three more lines from the 2009 Experiment 1 which demonstrated insufficient height reduction but which had interesting yield results. These six lines were assessed on medium scale field trials (Experiment 2) and from these, the three lines obtained in 2008 experiment were assessed in real conditions large scale trials (Experiment 3) as they had obvious height reduction, high homogeneity and acceptable productivity. Nevertheless, the DH12 line had an exceptional and unexpected yield result.

Rice production and yield assays have to be repeated for at least three consecutive years and using replicates and control replicates, as field trial results are usually variable (Fig. 5). In our study, field dimensions were different in each experiment due to seed availability and they were placed in different locations due to field availability. Nevertheless, this three seed lines have been successfully submitted to Spanish registration process and other lines are still today under study.

\section{Selected lines}

The DH3 line differed from NRVC 980385 in a variety of traits: higher uniformity, shorter plants, shorter flag-leaf to spike distance (half the distance), wider and bigger spikes, however, with similar rice production. DH8 differed from NRVC 980385 in terms of early flowering and maturation (up to two weeks) and shorter height, although it had a similar yield. DH9 is highly uniform, shorter than NRVC 980385 but taller than the DH3 and DH8 lines. DH12 turned out to be the most interesting line as it was the most productive.

\section{Conclusions}

In conclusion, an in vitro protocol based on the anther culture technique has been designed and optimized to obtain DH lines for the Spanish Mediterranean temperate japonica variety NRVC 980385. This protocol allows one to move rapidly from the anther collection stage to large scale field trials, thereby achieving the production of field assessed DH lines in a much reduced time period. This can now be adapted to other temperate japonica rice cultivars in order to obtain improved lines, and therefore avoid long breeding and inbreeding processes. It can also be adapted to obtain selected DH lines from F1 or F2 hybrids. 


\section{Acknowledgements}

The authors would like to thank Roser Llaò for her work in the field trials, and Ginés Gomez (Càmara Arrossera del Montsià seed section president) for his generous help and advice. Also the authors wish to thank all the students that helped with the in vitro work. This work has been carried out as a part of a ORYCAMB PROJECT A.I.E. between CÀMARA ARROSSERA DEL MONTSIÀ I SECCIÓ DE CRÈDIT SCCL and ORYZON GENOMICS S.A. called “Mejora de la variedad Montsianell de Denominación de Origen Protegida para perpetuar la producción de arroz tradicional en el Delta del Ebro" supported by ACC1Ò (Agencia Catalana de Apoyo a la Competitividad de la Empresa, Generalitat de Catalunya). S.N. would also like to thank OPTIMA and PALEOISOCROP projects for their financial support. 


\section{Reference list}

Abbasi FM, Akbar K, Rehman MU, Khan MT, Iqbal S, Fatima A, Noshine, Ali H, Abbasi MF (2011) Cytological characterization of anther culture derived plants from the interspecific crosses between Oryza sativa $\mathrm{x}$ Oryza australinesis and Oryza sativa x Oryza brachyantha. African Journal of Biotechnology 10 (17):3269-3273

Afza R, Shen M, Zapata-Arias FJ, Xie JH, Fundi HK, Lee KS, Bobadilla-Mucino E, Kodym A (2000) Effect of spikelet position on rice anther culture efficiency. Plant Science 153 (2):155-159. doi:10.1016/s01689452(99)00266-6

Agache S, Bachelier B, Buyser J, Henry Y, Snape J (1989) Genetic analysis of anther culture response in wheat using aneuploid, chromosome substitution and translocation lines. Theoretical and Applied Genetics 77 (1):7-11. doi:10.1007/bf00292308

Asea G, Onaga G, Phiri NA, Karanja DK (2010) Quality Rice Seed Production Manual

Bagheri N, Babaeian-Jelodar N, Ghanbari A (2009) Evaluation of Effective Factors in Anther Culture of Iranian Rice (Oryza sativa L.) Cultivars. Biharean Biologist 3 (2):119-124

Bishnoi U, Jain RK, Rohilla JS, Chowdhury VK, Gupta KR, Chowdhury JB (2000) Anther culture of recalcitrant indica $\times$ Basmati rice hybrids. Euphytica 114 (2):93-101. doi:10.1023/a:1003915331143

BOE (2010) Orden ARM/3368/2010, de 27 de diciembre, por la que se aprueba el Reglamento Técnico de Control y Certificación de semillas de cereales. 20060, vol ARM/3368/2010. Ministerio de medio ambiente y medio rural y marino, Boletín Oficial del Estado

Bohanec B (2003) Ploidy determination using flow cytometry. Doubled haploid production in crop plants: a manual. Kluwer Academic Publishers, Dordrecht

Botchey SA (1988) Rice seed production at the West Africa Rice Development Association. In: IRRI (ed) Rice seed health. West Africa Rice Development Association, Manila Philippines, pp 299-314

Brar D, Khush G (2006) Cytogenetic Manipulation and Germplasm Enhancement of Rice (Oryza sativa L.). In: Genetic Resources, Chromosome Engineering, and Crop Improvement. Genetic Resources Chromosome Engineering \& Crop Improvement. CRC Press, pp 115-158. doi:10.1201/9780203489260.ch5

Briggs FN, Knowles PF (1967) Introduction to plant breeding. Introduction to plant breeding. Reinhold Publishing Corporation, New York

Cai XS, Chen LZ (1984) The effects of cold shock and liquid medium on callus formation in rice anther culture. Journal of Agricultural Research of China 33 (1):24-29

Campos GL, F JC, Batalla JA (1966) Variedades de arroz cultivadas en España. Federación Sindical de Agricultores Arroceros de España,

Català MM, Jardí M, Pla E (2007) Evolución de las variedades de arroz cultivadas en el Delta del Ebro durante los últimos 20 años. Agrícola Vergel 303 (26):132-135 
Català MM, Pla E, Martínez M, Tomás N (2010) Estudio comparativo de la nascencia de cuatro variedades de arroz con diferentes manejos del agua. Agrícola Vergel 339 (29):212-215

Català MM, Tomàs N, Martínez M, Pla E (2009) Valoración agronómica de nuevas variedades de arroz. Ensayos en el Delta del Ebro: 2004-2008 (Agronomic evaluation of new rice varieties. Studies in the Ebro Delta). Agrícola vergel 327 (28):161-166

Chen C-C (1977) In vitro development of plants from microspores of rice. In Vitro Cellular \& Developmental Biology - Plant 13 (8):484-489. doi:10.1007/bf02615140

Chen C-C, Chen C-M (1979) A method for anther culture of rice. Methods in Cell Science 5 (2):1051-1053. doi:10.1007/bf00919787

Chen C-C, Tsay HS, Huan CR (1991) Factors affecting androgenesis in rice (Oryza sativa). Biotechnology in agriculture and forest 14:193-215

Chen CM, Chen C-C, Lin MH (1982) Genetic analysis of anther-derived plants of rice. Journal of Heredity 73 (1):49-52

Cho MS, Zapata FJ (1988) Callus formation and plant regeneration in isolated pollen culture of rice (Oryza sativa L. cv. Taipei 309). Plant Science 58 (2):239-244. doi:10.1016/0168-9452(88)90014-3

Chu CC, Wang CC, Sun CS, Chen H, Yin KC, Chu CY, Bi FY (1975) Establishment of an efficient medium for anther culture of rice through comparative experiments on the nitrogen sources. Scientia Sinica 18 (5):659-668

CIAT (ed) (1981) Producción y beneficio de semilla certificada de arroz; guía de estudio para ser usada como complemento de la Unidad Audiotutorial sobre el mismo tema. Centro Internacional de Agricultura Tropical, Cali, Colombia

Coca M, Bortolotti C, Rufat M, Penas G, Eritja R, Tharreau D, del Pozo AM, Messeguer J, San Segundo B (2004) Transgenic rice plants expressing the antifungal AFP protein from Aspergillus giganteus show enhanced resistance to the rice blast fungus Magnaporthe grisea. Plant Mol Biol 54 (2):245-259. doi:10.1023/b:plan.0000028791.34706.80

Courtois B (1993) Comparison of single seed descent and anther culture-derived lines of 3 single crosses of rice. Theoretical and Applied Genetics 85 (5):625-631

Germana MA (2011) Gametic embryogenesis and haploid technology as valuable support to plant breeding. Plant Cell Rep 30 (5):839-857. doi:10.1007/s00299-011-1061-7

Goulart I, Pacheco MT, Nunes AL, Merotto A (2012) Identification of origin and analysis of population structure of field-selected imidazolinone-herbicide resistant red rice (Oryza sativa). Euphytica 187 (3):437-447. doi:10.1007/s10681-012-0738-5

Gupta HS, Borthakur DN (1987) Improved rate of callus induction from rice anther culture following microscopic staging of microspores in iron alumhaematoxylin. Theoretical and Applied Genetics 74 (1):95-99. doi:10.1007/bf00290090

Guzman M, Arias FJZ (2000) Increasing anther culture efficiency in rice (Oryza sativa L.) using anthers from ratooned plants. Plant Science 151 (2):107114. doi:10.1016/s0168-9452(99)00204-6

Heberlebors E (1985) In vitro haploid formation from pollen: a critical review. Theoretical and Applied Genetics 71 (3):361-374 
Herath HMI, Bandara DC (2011) Anther culture performance in selected high yielding indica (of Sri Lanka) and japonica rice varieties and their inter sub-specific hybrids. Journal of the National Science Foundation of Sri Lanka 39 (2):149-154

Herath HMI, Bandara DC, Samarajeewa PK, Wijesundara DSA (2009) The effect of plant growth regulators on anther culture response and plant regeneration in selected Sri Lankan Indica rice varieties, Japonica varieties and their inter-sub specific hybrids. Tropical Agricultural Research 20:243-250

Herruzo AC (1986) Evaluation of agricultural research: research relating to rice cultivation in Spain (Evaluacion de la investigacion agraria: aplicacion al cultivo del arroz en Espana.). Comunicaciones INIA, Economia y Sociologia Agraria (19):182pp.-182pp.

IRRI (ed) (1988) Rice Seed Health. Proceedings of the international Workshop on Rice Seed Health, Manila

Islam MM, Adhikary SK, Purnendu G, Rahman MM, Noor-e-Alam S (2004) Effect of plant growth regulators on callus induction and plant regeneration in anther culture of rice. Pakistan Journal of Biological Sciences 7 (3):331-334

Javed MA, Misoo S, Mahmood T, Haider MS, Shah AH, Rashid VN, Iqbal J (2007) Effectiveness of alternate culture temperatures and maltose in the anther culture of salt tolerant indica rice cultivars. 8th African Crop Science Society Conference, El-Minia, Egypt, 27-31 October 2007:753757

Jennings PR, Coffman WR, Kauffman HE (1979) Rice improvement. Rice improvement. International Rice Research Institute (IRRI), Los Baños, Laguna, Philippines

Kaloumenos NS, Capote N, Aguado A, Eleftherohorinos IG (2013) Red rice (Oryza sativa) cross-resistance to imidazolinone herbicides used in resistant rice cultivars grown in northern Greece. Pesticide Biochemistry and Physiology 105 (3):177-183. doi:10.1016/j.pestbp.2013.01.008

Karim NH, Zapata FJ (1990) One-step rice plantlet development through anther culture. Indian Journal of Plant Physiology 33 (2):119-124

Keller M, Karutz C, Schmid JE, Stamp P, Winzeler M, Keller B, Messmer MM (1999) Quantitative trait loci for lodging resistance in a segregating wheat x spelt population. Theoretical and Applied Genetics 98 (6-7):1171-1182. doi:10.1007/s001220051182

Khush GS (2001) Green revolution: the way forward. Nature Reviews Genetics 2 (10):815-822. doi:10.1038/35093585

Kumari M, Clarke HJ, Small I, Siddique KHM (2009) Albinism in Plants: A Major Bottleneck in Wide Hybridization, Androgenesis and Doubled Haploid Culture. Critical Reviews in Plant Sciences 28 (6):393-409. doi:10.1080/07352680903133252

Lai PC, Tsay HS, Chi NC (1980) The relationship between anther browning and callus formation in rice anther culture. Journal of Agricultural Research of China 29 (2):137-146

Lentini Z, Martínez C, Roca W (1997) Cultivo de anteras de arroz en el desarrollo de germoplasma. Fundación polar. Centro Internacional de agricultura tropical., Caracas 
Marassi MA, Bovo OA, Lavia GL, Mroginski LA (1993) Regeneration of rice double haploids using a one-step culture procedure. Journal of Plant Physiology 141 (5):610-614

Marfa V, Mele E, Gabarra R, Vassal JM, Guiderdoni E, Messeguer J (2002) Influence of the developmental stage of transgenic rice plants (cv. Senia) expressing the cry1B gene on the level of protection against the striped stem borer (Chilo suppressalis). Plant Cell Rep 20 (12):1167-1172. doi:10.1007/s00299-002-0452-1

Martinez CP, Victoria FC, Amezquita MC, Tulande E, Lema G, Zeigler RS (1996) Comparison of rice lines derived through anther culture and the pedigree method in relation to blast (Pyricularia grisea Sacc) resistance. Theoretical and Applied Genetics 92 (5):583-590. doi:10.1007/s001220050167

Masajo TM, Alluri K, Claassen SL (1988) Rice seed production at the International Institute of Tropical Agriculture. In: IRRI (ed) Rice seed health. Manila, Philippines, pp 291-298

Mercy ST, Zapata FJ (1986) Chromosomal behavior of anther culture derived plants of rice. Plant Cell Rep 5 (3):215-218

Messeguer J (2003) Gene flow assessment in transgenic plants. Plant Cell, Tissue and Organ Culture 73 (3):201-212. doi:10.1023/a:1023007606621

Moon HP, Kang KH, Choi IS, Jeong OY, Hong HC, Choi SH, Choi HC (2003) Comparing agronomic performance of breeding populations derived from anther culture and single-seed descent in rice. Advances in rice genetics, Los Banos, Laguna, Philippines, 22-27 October 2000. doi:10.1142/9789812814319_0001

Munoz D, Rosero MJ (1988) The rice seed production system in Columbia In: IRRI (ed) Rice seed health. Manila, Philippines, pp 265-275

Murashige T, Skoog F (1968) A Revised Medium for Rapid Growth and Bio Assays with Tobacco Tissue Cultures. Physiologia Plantarum 15:473-497

Niizeki H, Oono K (1968) Induction of Haploid rice plant from anther culture. Proc Jpn Acad 44:554-557

Niroula RK, Bimb HP (2009) Effect of Genotype and Callus Induction Medium on Green Plant Regeneration from Anther of Nepalese Rice Cultivars. Asian Journal of Plant Sciences 8 (5):368-374

Raina SK, Zapata FJ (1997) Enhanced anther culture efficiency of indica rice (Oryza sativa L.) through modification of the culture media. Plant Breeding 116 (4):305-315. doi:10.1111/j.1439-0523.1997.tb01004.x

Rao YY (1988) Rice seed production in India. In: IRRI (ed) Rice seed health. Andhra Paresh State Seeds Development Corporation Ltd., Manila, Philippines, pp 253-263

Reddy VS, Leelavathi S, Sen SK (1985) Influence of genotype and culture medium on microspore callus induction and green plant regeneration in anthers of Oryza sativa. Physiologia Plantarum 63 (3):309-314

Sasaki A, Ashikari M, Ueguchi-Tanaka M, Itoh H, Nishimura A, Swapan D, Ishiyama K, Saito T, Kobayashi M, Khush GS, Kitano H, Matsuoka M (2002) Green revolution: A mutant gibberellin-synthesis gene in rice New insight into the rice variant that helped to avert famine over thirty years ago. Nature 416 (6882):701-702. doi:10.1038/416701a

Shahjahan AKM, Karim NH, Nahar MA, Hoque MZ, Miah SA (1992) Studies on the callus induction efficiency of rice (Oryza sativa L.) anthers. Bangladesh Journal of Botany 21 (2):239-246 
Shimada T, Otani M, Ikuta Y (1999) Investigation of the callus induction medium and the regeneration medium in rice anther culture. Japanese Journal of Crop Science 68 (1):151-154

Shivrain VK, Burgos NR, Gealy DR, Moldenhauer KAK, Baquireza CJ (2008) Maximum outcrossing rate and genetic compatibility between red rice (Oryza sativa) biotypes and ClearfieldTM rice. Weed Science:56:807-813.

Silva JMI, Castillo PS, Javier EL (1988) The Philippine rice seed production system. In: IRRI (ed) Rice seed health. Laguna Seed Growers' Association, Manila, Philippines, pp 247-251

Talebi R, Rahemi MR, Arefi H, Nourozi M, Bagheri N (2007) In vitro plant regeneration through anther culture of some Iranian local rice (Oryza sativa L.) cultivars. Pak J Biol Sci 10 (12):2056-2060

Torres O, Salazar M, Navas M, Álvarez R, Reyes E, Moreno O, Delgado N, Torrealba G, Acevedo M, Castrillo W (2006) Metodología para la obtención, mantenimiento y producción de semilla de arroz clase genética. INIA divulga 9:14-16

Trejo-Tapia G, Amaya UM, Morales GS, Sanchez AD, Bonfil BM, RodriguezMonroy M, Jimenez-Aparicio A (2002a) The effects of cold-pretreatment, auxins and carbon source on anther culture of rice. Plant Cell Tissue and Organ Culture 71 (1):41-46. doi:10.1023/a:1016558025840

Trejo-Tapia G, Maldonado-Amaya U, Jimenez-Aparicio A, Blanqueto-Illescas M, Salcedo-Morales G, Martinez-Bonfil BP, Jesus-Sanchez Ad (2002b) Effect of time at low temperature treatment and growth regulators on regeneration of plants from anthers of rice Oryza sativa L. (Japonica H2005 cultivar). Agrociencia (Montecillo) 36 (4):441-449

Wang CC, Sun CS, Chu CC, Wu SC (1981) Studies on the albino pollen plantlets of rice. Proceedings of symposium on plant tissue culture:149-160

Wankhade SD, Cornejo MJ, Mateu-Andres I (2010) Microsatellite marker-based genetic variability in Spanish rice cultivars and landraces. Spanish Journal of Agricultural Research 8 (4):995-1004

Yamagishi M (2002) Heterogeneous plastid genomes in anther culture-derived albino rice plants. Euphytica 123 (1):67-74. doi:10.1023/a:1014493316433

Yamagishi M, Otani M, Higashi M, Fukuta Y, Fukui K, Yano M, Shimada T (1998) Chromosomal regions controlling anther culturability in rice $\begin{array}{lllll}\text { (Oryza sativa } & \text { L.). } & \text { Euphytica } & 103 & \text { (2):227-234. }\end{array}$ doi:10.1023/a:1018328708322 


\section{Tables}

Table 1. Field size of different experiments and DH lines assayed during 2008, 2009 and 2010 (see details in Material and Methods).

\begin{tabular}{clll} 
Experiment & Field size & DH lines assayed & Years \\
\hline \multirow{2}{*}{ Small } & DH1 to DH10 & 2008 \\
& DH11 to DH20 & 2009 \\
\hline \multirow{2}{*}{ Medium } & DH3, DH8, DH9 & 2009 and 2010 \\
& & DH12, DH16, DH18 & 2010 \\
\hline \multirow{2}{*}{3} & Large & $\mathrm{DH} 3, \mathrm{DH}, \mathrm{DH} 9$ & 2010
\end{tabular}

Table 2. Yield data from experiments 2 and 3. *Average NRVC 980385 seed production yield in 2010. NRVC 980385 cultivar was used as control.

\begin{tabular}{c|cc|cc|rc}
\multicolumn{2}{c}{} & \multicolumn{2}{c}{ Experiment 22009} & \multicolumn{2}{c}{ Experiment 22010} & \multicolumn{2}{c}{ Experiment 32010} \\
Line & \multicolumn{1}{c}{ Surface $\left(\mathrm{m}^{2}\right)$} & Yield $(\mathrm{Kg} / \mathrm{Ha})$ & \multicolumn{1}{c}{ Surface $\left(\mathrm{m}^{2}\right)$} & \multicolumn{1}{c}{ Yield $(\mathrm{Kg} / \mathrm{Ha})$} & \multicolumn{1}{c}{ Surface $\left(\mathrm{m}^{2}\right)$} & Yield $(\mathrm{Kg} / \mathrm{Ha})$ \\
\hline DH3 & 4982.7 & 6966.16 & 1835.4 & 7273.62 & 47807.4 & 7299.77 \\
DH8 & 2333.0 & 6763.82 & 1830.4 & 7659.53 & 44517.9 & 8106.16 \\
DH9 & 4060.7 & 7368.12 & 1919.4 & 6892.78 & 44649.5 & 7091.98 \\
DH12 & $\mathrm{n} / \mathrm{a}$ & $\mathrm{n} / \mathrm{a}$ & 1325.5 & 9038.10 & $\mathrm{n} / \mathrm{a}$ & $\mathrm{n} / \mathrm{a}$ \\
DH16 & $\mathrm{n} / \mathrm{a}$ & $\mathrm{n} / \mathrm{a}$ & 1242.0 & 7181.96 & $\mathrm{n} / \mathrm{a}$ & $\mathrm{n} / \mathrm{a}$ \\
DH18 & $\mathrm{n} / \mathrm{a}$ & $\mathrm{n} / \mathrm{a}$ & 1642.5 & 6295.28 & $\mathrm{n} / \mathrm{a}$ & $\mathrm{n} / \mathrm{a}$ \\
CONTROL & 10964.5 & 7753.20 & 5745.5 & 7019.41 & $\mathrm{n} / \mathrm{a}$ & $6863.00^{*}$
\end{tabular}




\section{Figure captions}

Fig. 1. Obtaining in vitro rice DH lines and subsequent field trials. a) Donor plant material, b) shoot selection, c) spikelet selection, d) microspore stage determination, e) anther plating, f) callus grown from anther culture, g) plantlet regeneration from anther derived calli, h) plant propagation, i) acclimatization to greenhouse conditions, j) experiment 2 (year 2009) on DH8 line, k) experiment 3 (year 2010) on DH8 line, l) experiment 4 (year 2010) on DH8 line.

Fig. 2. Schematic representation of NRVC 980385 rice cultivar anther culture schedule to obtain DH lines and its propagation from June 2007 until February 2008. Total days (d) per step are indicated. $\mathrm{Pd}=$ Plantlet development $\mathrm{Pa}=$ Ploidy analysis took place in 5 days.

Fig. 3. Height average for Experiment 1 tested lines and NRVC 980385 controls in both 2008 (a) and 2009 (b) trials. Each bar is the average of at least 8 replicates \pm standard error.

Fig. 4. Height average for Experiment 2 tested lines and NRVC 980385 controls in (a) 2008 trial and (b and c) 2009 trials. Each bar is the average of at least 8 replicates \pm standard error.

Fig. 5. Yield data from primary selected lines. Experiment 2 data from 2009 assay (a) and 2010 assay (b) is compared to NRVC 980385 control grown by the lines and cultured the same way. Experiment 3 data (c) is compared to NRVC 980385 average production in seed production fields in the same year. 


\section{Supplementary data}

Figure S1. Coulter EPIC XL flow cytometer results using Summit Software v4.3. a dihaploid sample, $\mathbf{b}$ haploid sample.

Figure S2. Schematic of the design of the 2008 (a) and 2009 (b) Experiment 1 field trials. Eighteen $10 \mathrm{~m}^{2}$ plots (2 meters x 5 meters) were reserved for assessed lines and NRVC 980385 controls. Their position is indicated. The bottom margin of the field corresponds to the 5 meters width access road, the distance from plots to the road was only 15 meters. A minimum 15 meters distance between lines and 20 meters to adjacent fields was designed to avoid gene flow-mediated hybridization.

Figure S3. Anther culture and lines tested in the study.
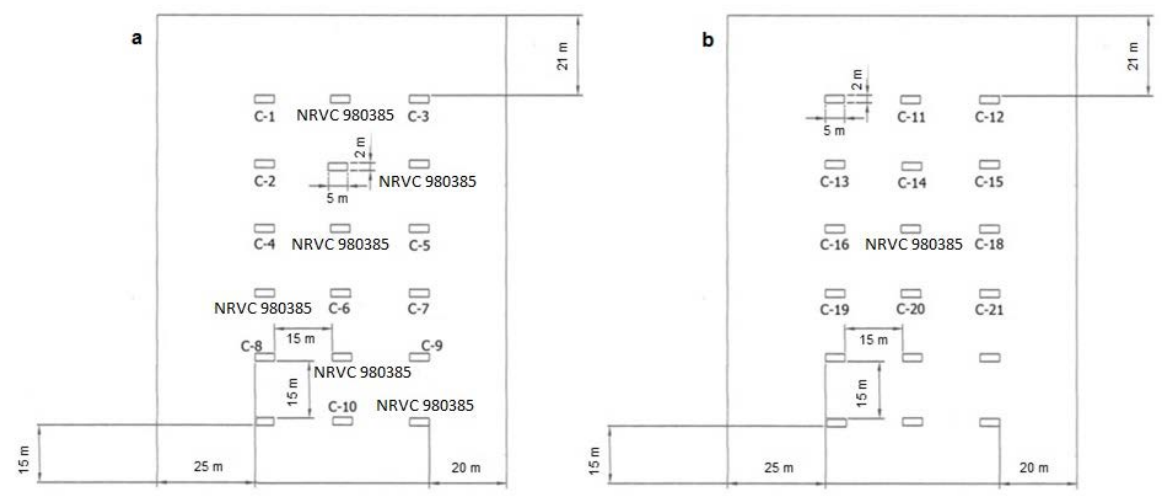